\title{
Strengths and Challenges of Arts-Based Programming for Individuals With Alzheimer's and Related Dementias
}

\author{
Sara Clarke-Vivier, Corie Lyford, and Lynn Thomson
}

\begin{abstract}
Through the perspectives of a museum educator, an art educator, and an educational researcher, this article explores the evolution of shared definitions of "well-being" in the development of a museum- and arts-based program for adults with Alzheimer's disease and related dementias (ADRD). By piecing together the authors' first-person reflections on pivotal program design moments with images, participant quotes and reflections, and emerging quantitative data, this bricolage inquiry provides insight into the complex and sometimes competing conceptions of wellness and learning that arise in designing programming with and for this population and their caregivers.
\end{abstract}

\section{Museum Programming for Well-Being}

The purpose of this article is to shed light on the tensions and complicated relationships between learning and well-being in a museum- and arts-based program for adults with Alzheimer's disease and related dementias (ADRD) and their caregivers by exploring the collaborative development of one program in a small New England art museum. Alzheimer's is a progressive and debilitating neurodegenerative disease that affects memory, vision, and dexterity. These cognitive and physiological symptoms can also contribute to social and emotional difficulties, including reduced confidence, mood variations, and feelings of social isolation. As the Baby Boomer generation advances in age, the Alzheimer's Association anticipates that the number of Americans with Alzheimer's will increase from the current historic high of 5.4 million to a projected 138 million (Alzheimer's Association, 2017). These projections, paired with increased attention to the wellbeing for these of individuals and their caregivers, shed light on the need for the development of diverse and supportive programming opportunities (Marshall \& Hutchinson, 2001). It is in this space that community organizations like museums have stepped in (AAM, 2013).

Museum art programs for individuals with ADRD, which focus on engaging individuals in positive, shared learning experiences, were popularized by the Metropolitan Museum of Art's "Meet me at MoMA" and now exist in varying forms in art and other museums around the world. This type of programming quickly became so popular that in 2013 the American Alliance of Museum (AAM) issued a report called "Museums on Call: How Museums Are Addressing Health Issues," which devotes a whole section to work with this population. In their overview of programs across the United States, the AAM identified three main activities that museums are implementing for adults with Alzheimer's: offering special tours, facilitating hands-on art making, and facilitating art experiences designed to trigger memoires using 
artwork or music as prompts. These programs, generally held in museum settings, are either participatory (characterized by interactive, hands-on participation: art making, and interactive discussion) or nonparticipatory (characterized by more passive activities such as observing art). While most programs are described as supporting individuals with Alzheimer's as a primary focus, many also offer benefits and supports to family members and caregivers (AAM, 2013).

Overall, the goals of museum- and art-based programs for individuals with ADRD are closely linked with ideas of health and well-being. Improvements in quality of life, for example, such as decreases in anxiety, improvements in mood, and development of social connectedness and community, often undergird program goals (Selberg, 2015).

These improvements can be broken into two categories: decreasing social isolation and increasing selfesteem and positive mood for individuals living with ADRD and their caregivers. These goals are achieved through programming that foregrounds the development of communities and networks outside of the home that are less stigmatizing and more social than medical locations (Rosenberg, 2009; Flatt et al., 2015), and thus reduce stigma from disease symptoms (Rosenberg, 2009; Mangione, 2013). By centering these goals, programs aim to create safe spaces for conversation and connection where communities are brought together by disease without being entirely defined by the disease. Self-esteem related goals are supported by providing programming that can sustain interest and engagement but that does not have the disease, or its symptoms, at the center (Flatt et al., 2015; Selberg, 2015); through providing physical and psychological respite for caregivers (Rosenberg, 2009); and by creating an opportunity for equal participation for both caregivers and people with ADRD that affirms and accepts individual voice (Rosenberg, 2009; Selberg, 2015).

Though these programs are often hosted in museum education departments, the overarching objectives seek to strike a (sometimes uncomfortable) balance between the educative, the palliative, and the therapeutic (Selberg, 2015). This balance was one that we wrestled with as we developed the Alzheimer's Café program, a collaboration between the Currier Museum of Art and Easter Seals New Hampshire. The sometimes-uncomfortable tensions between education and well-being emerged at key moments in our programming between stakeholders, practitioners, evaluators, and participants. This paper brings the reader in close to the moments where these complexities were negotiated. In an effort to understand the diversity of voices and experiences at play in these negotiations, we undertake their presentation using a methodological bricolage (Denzin \& Lincoln, 1999; Kincheloe, 2005; Rogers, 2012). Here, the interweaving of personal reflection, analytic writing, participant quotes, photographs, and student art images both highlights the artistic goals and aesthetic currents of the Café project and appreciates the complexity of the design experience. Thus, our text centers on a series of moments in an effort to understand "well-being" and "learning" in this context. 


\section{In the Beginning}

\section{Snapshot one: Corie, art program coordinator and instructor}

I have loved making and admiring art since I was a small child. I announced for the first time that I was going to be an art teacher when I was only five years old. My creative side was nurtured and encouraged by all my family, but by my paternal grandmother, my Oma. Oma grew up in the Netherlands where she enjoyed many amazing art opportunities. She grew up in a house where a Rembrandt hung proudly on the wall. She visited museums, took private art lessons, and passed this love, particularly for painting, onto me, her namesake and only granddaughter.

In the last few years, my Oma began suffering from dementia. Even as she lost her grasp on names and her knowledge of whether she had eaten breakfast, she maintained her love of art. We filled her room at her nursing home with her own paintings as well as artwork done by my brother and myself. One of the last lucid conversations I had with Oma was about the beauty of nature and how it motivates us to create. We lost my grandmother, at the age of 97, just one week after that conversation.

I feel privileged to work with seniors in my job as an art educator. In them I see my grandmother. I understand the peace and joy to be found through the arts because my Oma taught me that.

\section{Corie, in the classroom}

I'm fairly nervous as I roll my cart of art supplies down the hallway at the adult care facility. I've taught painting and collage lessons many times, but never to a group of senior citizens with Alzheimer's. I roll my cart into a room that looks like a comfortable, cozy living room at someone's house, including a quilt hung on the wall and a fireplace in the corner. This is the room where many of the ladies that I am about to meet spend most of their day, and it is the room where we will have our art classes. The room is hectic, with half of the women leaving to go to a different program for the time being, and half staying to be a part of our art group. I try to stay out of the way and quietly start setting up trays of paint, paintbrushes, glue sticks, oil pastels, and paper. We'll be doing a Degas-inspired torn paper ballerina collage; I've worked hard to put together a project that will be accessible, manageable, and most importantly for me, fun for all of my students. I start to relax.

I look up and notice a woman, one of my students whose name is Doris, looking my way. To be more accurate, she is glaring at me. She angrily demands to know what I'm doing there. I tell her that I'm there to do a fun art project with everyone. She tells me in no uncertain terms that she cannot and will not paint, and that I can't make her.

If I was fairly nervous before, I'm terrified now. 
Corie's nerves belie the sheer volume of preparatory work and thought that she and a large interdisciplinary team of others had put into developing this effort. Though the museum had offered on-site programming for individuals with Alzheimer's and their families, it had been largely modeled on nonparticipatory image- and gallery-based discussions of art. Hesitations to include more interactive art making or music into the program hinged largely on anxieties about providing experiences that would support the mission without designing a program that seemed as though it was meant for children, or that felt like art-therapy.

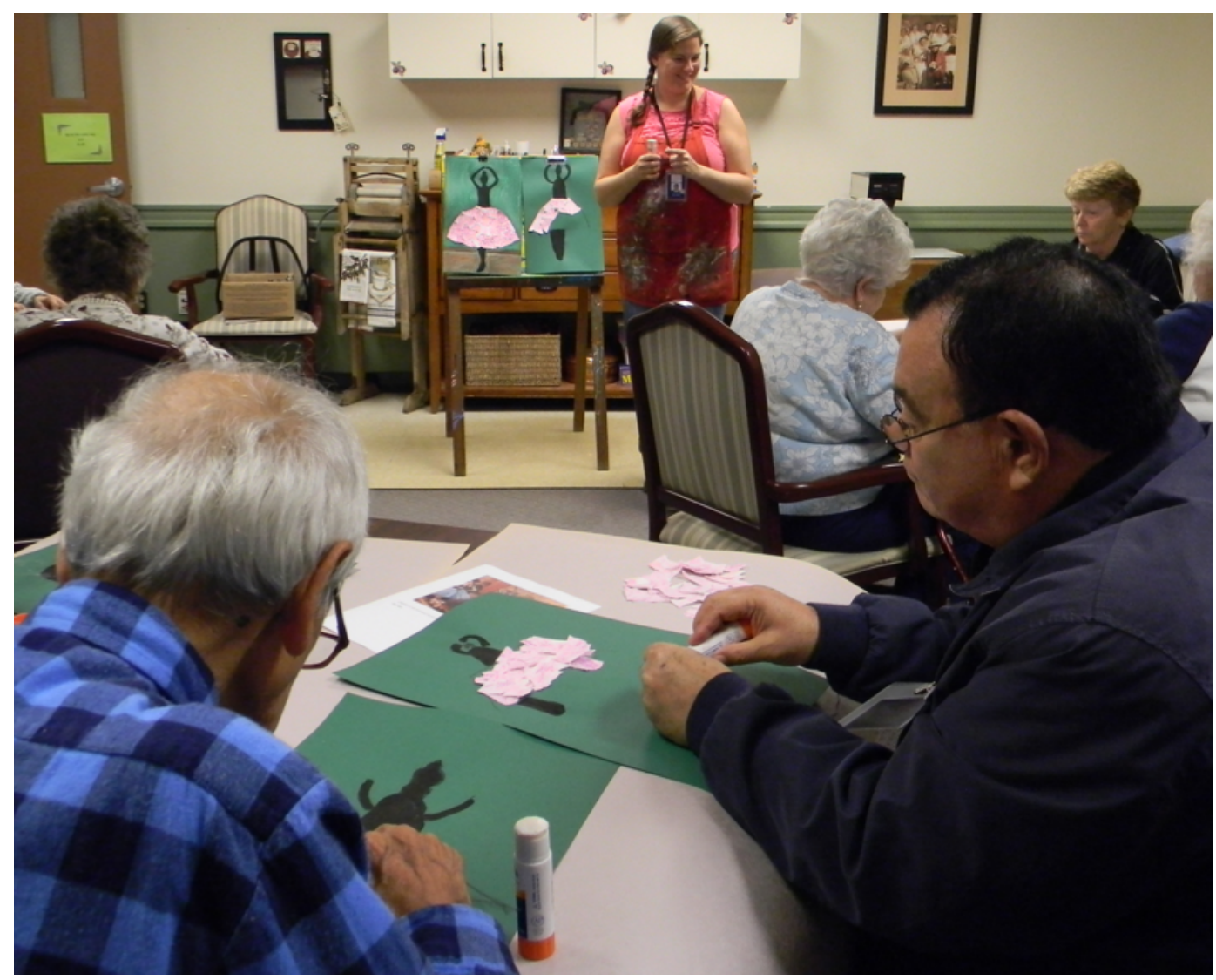

Fig. 1: Corie facilitates a Degas-inspired lesson in the Easter Seals classroom. October 2015. Photo by Barbara Sargent.

The stated mission, to provide accessible creative and social experiences that "connect people to the joys of creativity, to ennoble them with a sense of accomplishment, and to reconnect them to their lives and loved ones through resulting conversations and storytelling" (Currier Museum of Art n.d.) was one we had successfully achieved in a nonparticipatory way. But as an art museum with a strong commitment to artmaking education, a hands-on component had to be a part of our next steps. How could we do this without offering programming that was overly simplistic, or perceived as childish or demeaning to the adult participants and their caregivers? A new partnership opportunity with a local adult day program at Easter Seals $\mathrm{NH}$ provided the museum and the day program organizers an opportunity to think about how art making could be integrated with the gallery-based programming into a sustained art-centered experience for day program participants with ADRD in ways that supported our goals for well-being while extending program offerings. 
Our team, comprising artists, art educators, social workers, direct service providers, program directors, and an educational researcher, spent months defining and fine-tuning a shared mission of connecting patients with ADRD to art. The existing museum-based program became a jumping-off point. We would continue to have a monthly visit to the Currier centered on an opportunity to look closely at and discuss fine art images, and spend time looking in the galleries together. Lynn, one of the Café's facilitators, would choose images that all people might connect to; familiar scenes of families, children, parties, holidays, and pets that would foster participation, sharing, and dialogue. This anchoring museum experience was essential to meeting one of the program's goals of connecting caregivers and loved ones to their family members with ADRD, as well as to one another in a nonclinical setting, with the overall vision that they would come to see the museum as a space in the community that they could safely and confidently navigate at other times.

With 12 participants from Easter Seals New Hampshire's ADRD day program as our participants, we decided to run a three-month pilot program that integrated the established museum visit with weekly artmaking classes at the program facility, a comfortable classroom familiar to all. The vision for the project seemed straightforward: three weeks making art in the day program classroom, and a once-a-month field trip to the museum for a visit. The museum's Art Education Director Bruce McColl described the program and its components:

In the classroom, students will be provided the experience of working with professional teachers, inspired by masterworks in the collection, and given the license to explore technique and expression. In this situation, students are afforded a space for self-expression-which is reparative and communicative in nature. In the galleries, as a visitor to masterworks, visitors will be provided the opportunity to assess, question and appreciate our collections. (B. McColl, personal communication, January 2017)

Corie's snapshot reflection and photograph above provide a window into this space; a cozy room, familiar to all participants, where three weeks of art programming would happen between each museum visit. Corie designed the art programming to connect to items in the museum's collection while also maintaining a relaxing atmosphere where individuals could use art as a way to communicate, to engage with different forms of communication, and experience individual success in art making. To our minds, these social experiences centered on art promoted some core components of well-being that are often difficult to maintain for individuals with ADRD; self-expression, positive mood, and social engagement.

The ideas were in place, and the design team felt ready. If participants were socially engaged, participating in the art project, and feeling good, we felt confident that the program would achieve our goals. What it was like when we began was different in ways we perhaps could not have anticipated; the first, Doris's assertion: "You can't make me paint." 


\section{Snapshot two: Sara, educational researcher}

I spent the beginning part of my teaching career working at a non-public residential school with children who had experienced trauma. Our classroom in the woods was separate from the challenges of school, family and community life. In that separation we pursued wellness. My students, adolescent boys called conduct disordered and emotionally disabled often found an opening in the arts. We composed a literary magazine, used the playground theatre to stage an all-male production of Our Town, and had rock concerts on a hodgepodge of second-hand musical equipment. I make no claim that anyone was cured, or even transformed in those moments. But we experienced them together and in them we were all more well.

Within that separation existed a tension. The space that on one hand granted us freedom and flexibility to pursue wellness did not buffer us from the expectations of the world away from the woods. Students were required to meet state and national standards, to pursue learning that looked and felt like the learning that was so often implicated in their own traumatic experiences and the undoing of their wellness. My role was first to facilitate these experiences, but second do document them and in so doing prove their relevance and demonstrate their worth. Succeeding in this pursuit became the central challenge of my early teaching career, and remains with me in the following moments.

\section{Sara, on the periphery}

Doing observational research can be awkward. I have been at the periphery of museum programming all summer, but that space is wider, more open. Here I am, sitting unobtrusively in a small room next to a fireplace, all quilts and programming supplies, watching, noting, questioning, reflecting. Trying to make sense of all the moving parts. It is my goal to devise an evaluation for the program- a means by which we can "prove" to future funders that the work we are doing is worthwhile; that participant well-being is achieved.

Today, I am watching participants tear bits of tissue paper, a wide array of pinks, into small tufts and glue them into a large triangle on green paper. These puffs would form the soft skirt of a ballerina, modeled off of a Degas print that Corie has shown the participants at the class's outset. The atmosphere is quiet but persistent; my observational checklist indicates that all 10 participants are socially engaged in their experiences. An occasional question or giggle erupts. A glib exchange between participants about what they personally know about ladies' skirts.

From the doorway the program director calls me over. She brings me into the adjacent lobby to show me a framed series of paintings, completed by several day program participants and a visiting artist. These are meticulous oil paintings; a red barn in the winter, snowy trees, clear neat brushstrokes, high fidelity to the model. Four precise copies of the immaculate original. I am immediately aware of the ballerinas, each hand-drawn by a participant, and their stubborn indifference to form. Some are blobby and wide, so very tall that their heads bump the margins, some limbless or standing on one thick sturdy leg.

With a frank and honest openness, the director asks me a question I am not prepared to answer. "What is the difference between the barns and the ballerinas?" Unsure, I probe for some subtext. "What will their children think when they bring home a fat tissue paper ballerina instead of a neat oil barn?" Her question holds in it an abiding anxiety, but also a loving care, a compassionate understanding of a type of relationship that neither Lynn, Corie, nor I have had to negotiate. 
In just this first week, two tensions emerge. First, what happens when what we think will work to support engagement and enjoyment for participants is met with "You can't make me"? As educators we've all met this challenge before, but something about the rosy optimism with which we approached this project left us surprised at its manifestation here. If participation is the key to both enhancing well-being and learning about art, and one refuses to participate, what can we do? Then, for those who do engage, who tear and paste and shape their ballerinas, what of the product? Although we began unified in shaping what the program would look like, after this first session we realized that despite our shared focus on process, on well-being and participation, we had not avoided the concern about the quality of our final product.

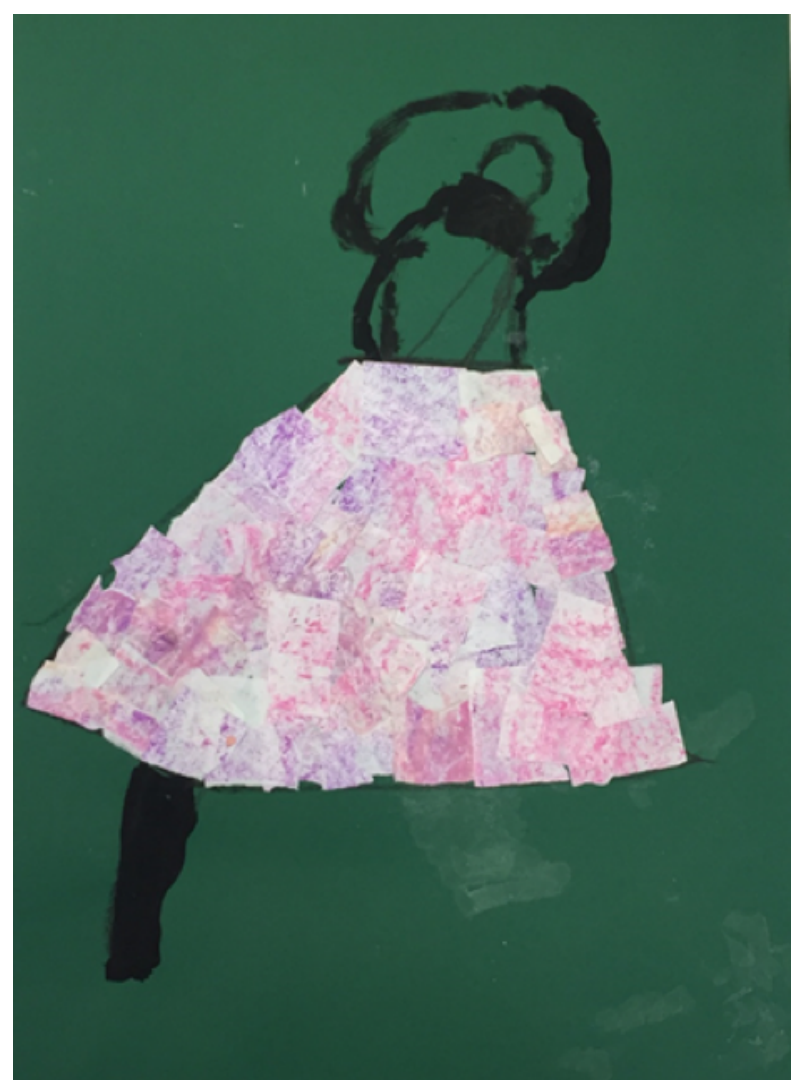

Fig. 2: Participant Barbara's ballerina. October 2016. Photo by Lynn Thomson.

What families and caregivers would think about the participant's art became a topic of major discussion. Originally, having a polished finished product was never in the goal. The program was intended to be process-oriented, grounded in positive pro-social engagement of individuals together in the classroom and with their caregivers in the museum. Some strongly felt that we could choose to have a polished project or an opportunity for self-expression, not both. The more we talked, the more we realized that self-expression was truly at the core of our beliefs about the program's impact, given Alzheimer's particularly devastating impact on an individual's ability to communicate. This communication, however central to our programming, was missing in our team's work. At the end of the day, our collaborators at Easter Seals were still handing art to caregivers who we too would face when they visited us in the museum. 
The word we relied on to encompass this concern was "childlike." There has been some exploratory research comparing the drawing skills of young children to those of adults with Alzheimer's. While children's skills improve with age on tasks such as drawing common objects and people, individuals with Alzheimer's drawings are most reminiscent of those done by four year olds; simple, few details, disorienting, prone to error and omission. Some, like those of the youngest children, lack clear representational intention, scribbles only (Bonoti, Tzouvaleka, Bonotis, \& Vlachos, 2015). Even experienced artists exhibit a series of changes and declines in their work as a result of dementiarelated symptoms that affect depictions of color, space, and contrast (Gretton \& Fftyche, 2014), resulting in art that no longer resembles their own earlier work. While resonant with our experiences, this research could not bridge the gap.

We had to ease the concern about the finished product. How? This question, more than others, shaped our expectations of what would count as strong research. The museum invited Sara to work on this project because of her experience in educational research and her willingness to navigate the complexities of measurement in informal learning environments. The introduction of an additional level of translation, the requirement to provide compelling evidence to an audience that now exceeded the confines of our team to include skeptical caregivers, meant that we would need to speak more than one research language.

\section{In the Middle}

\section{Snapshot three: Back in the classroom with Corie}

Fast forward and I'm back in that cozy room with another project. When I enter the room, Doris gives me a big smile and says, "Oh, it's the art girl." We are adding tempera paint to canvas to create a beach scene with a sunny sky. My back is turned to the table where Doris sits with three other ladies, but I quickly spin around when I hear Doris let out a loud scream. One of the helpers in the room has tried to add more yellow paint to Doris' paint tray and squeezed the bottle a bit too hard. The top has flown off and yellow paint has dumped onto the table and onto Doris' canvas. There is a stunned silence following Doris' scream. Doris herself breaks it as she bursts out laughing and apologizes to everyone for overreacting. She then takes the excess yellow paint on her canvas and turns it into a sun. She tells the helper not to worry. "I have just added value to my painting. I will sell it for a thousand dollars!" She looks at me, winks, and says, "No, I think two thousand." How far we've come in just a few weeks.

Moments of clarity, pleasure. In weeks, Doris, who would not be forced to make art, sets off a joyous commotion in the classroom. Corie has adjusted some of her plans as she comes to know her students. Ideas about their skills and deficits, evidenced in their time together and communicated by the day program staff, have given her more to work with. Trust grows in the collaboration, and communication opens. We observe the Easter Seals staff interacting with the participants, and gain confidence in ways to help participants engage with art making. How quiet or loud to speak. Whether to touch someone to get their attention, to guide their hands, to reorient them to the page. How to relax, to use the sense of humor that guides our other relationships, to interact by having fun and keeping it accessible without slipping into the trap of condescension, paternalism. 
Some ideas though, Corie cannot accept. An extensive use of stencils, having pre-drawn images on paper to be colored in by the participants, all ideas offered by helpful and hopeful staff attuned to the final product, are nonstarters. Undoubtedly these would yield better products; clearly, this type of support helped shape those neat little barns. Corie understood, however, that these tools would interfere with participant expression, with the type of joyful, social engagement we saw coming from more open experiences. Although tools were sometimes thoughtfully used to ensure that participants were successful in their projects, there had to be a balance between help from staff that ensured success and allowing for self-expression from the participants. It was also important to realize that "having success" in a project meant that each participant was able to complete a piece that they felt happy with and enjoyed doing, not creating a polished product that looked just like the teacher's sample piece. Since family members weren't a part of the art-making process, it became increasingly clear that for us to maintain the integrity of our collaborative vision, we had to find a way to share the process.

Health researcher Christine Putland (2008) makes the case that though feelings of joy and pleasure are among the most important and powerful outcomes of doing arts-based work, they can be difficult to quantify and measure. This is particularly the case in fields that focus on ways of understanding experience through medical or social models. As individuals immersed in the arts, we were attuned to these fleeting and qualitative experiences, used to describing them to people who wondered about the value of our work, but were not prepared to measure them in a way we believed would bridge the divide between a fat ballerina and a concerned caregiver. When Pam, the Program Coordinator at Easter Seals, arrived at a meeting with the Quality of Interactions Schedule (QUIS) (Dean, Proudfoot, \& Lindesay, 1993), we knew we were getting somewhere. Here, a validated measure that was being rolled out in the rest of the program could give a different dimension to our process, a numeric sense of what was happening as those art projects were being undertaken.

The QUIS was imperfect, as measurement tools tend to be. We were not staffed to have multiple raters, and as such had to be wary of what we reported in terms of validity. In a small room with so many people interacting, needing, working, helping, it could be hard to ensure that our periodic check-ins were happening systematically, that we had all the data points we would need to tell the story. Integrating this tool into our work, however, provided another braid in our narrative. We could say that people were engaged $90 \%$ of the time, and that $30 \%$ of that time was positive, social engagement, the type that resonated with our well-being goals.

Numbers complemented thick descriptions. Lesson plans contextualized shredded paper ballerinas. Quotes enlivened photographs. Art informed education and both were shaped by principles of health science. We came to understand that strong research needed to hold open these dichotomies and embrace interdisciplinary. Demonstrating meaning making in relationship to wellness required embracing a complex data research and data collection plan. So with observations and photos and paintings and quotes we documented the moments. The more we looked for well-being the more we saw: a shifting mood from the beginning to end of class, giggles, memories and retellings of stories and jokes, intense but peaceful concentration, a new willingness to experiment, to tolerate messy hands or lines that weren't quite straight. 
The documents which serve here as foundation for our writing became building blocks upon which open communication and critical reflection, revision, design, collaboration, and flexibility were built by participating parties. Our committee meetings were now informed by all types of "products"; participant art and observations and quotes and numbers. Slowly, the conversations about how we knew we were succeeding became decoupled from the art leaving the classroom. This was also the way that we came to settle in on our shared conception of well-being.

While collaboration allowed us to hit our stride with the day program participants, the first museum café program would be the litmus test of our ability to create these powerful moments of clarity, collaboration, and joy both in a novel environment and under the watchful gaze of participating caregivers and family members. Everyone's comfort zones would be pushed.

\section{Snapshot Four: Lynn, museum educator}

I know that art is a way to connect people. I have been fortunate enough in my career to work with individuals and groups who share that belief; through our work my commitment to it has been sustained. I was fortunate enough in my career to work in collaboration with a school that emphasized children as teachers in their own learning and encourage adults to listen to children's interests and use that as inspiration for how the classroom is structured. My collaborators believed in honoring the importance of what all individuals, regardless of age or skills, bring to the table. This belief was reiterated for me when I worked closely with Vietnam Veterans to develop programs in conjunction with an exhibition of photographs from the Vietnam War. Through careful listening in often very difficult conversations, we developed programs that involved veterans as the experts in the galleries and in the classroom and honored their experiences, often so different from our own. As I watched veterans and museum patrons have meaningful and powerful conversations, I was reminded again of the power of art to bring people together.

In the Alzheimer's Cafe I am doing something that would make my grandmother proud. As I watch her memory deteriorate and her anxiety grow, I am grateful for time with her that is social and that does not center around her illness. I work on this program and hope that through the power of art and discussion I am able to provide moments of joy - I know firsthand how important these moments are. 


\section{Lynn, in the gallery}

Each week when I plan the images to look at in the gallery I am nervous. I wonder if I have picked the right art works and the best questions to accompany the work that will elicit conversation. I wonder what people will say. This week we are looking at images that relate to sports and games. The theme is broad enough that everyone can connect in some way. Just last week, Corie had participants make and paint clay basketballs.

The group enters the room and settles in, greeted by myself and some volunteers who offer light refreshments. As she entered, Roberta seemed unhappy to be at the museum. She was agitated, posturing towards the staff member who accompanied her, resistant to enter. Once all are in their seats I start the discussion by saying hello, welcoming them and then looking at an image on the screen. Roberta's body language relaxed as the group opened up in discussion. She even participated. However after a while she became disinterested again and saying "This is stupid, why aren't we looking at the art work." Roberta was eager to leave.

We finished our discussion and went in to the galleries. Roberta's entire posture changed. She stood a taller, her face lit up. She engaged in the discussion.

"This is phenomenal!" she said.

"This is what I majored in.... What you want to do here is look at the dynamics of the picture, follow the lines" she told me.

"I'm analyzing the art work - that's what you do when you look at art," she told her friends.

Roberta assisted me in leading the rest of the gallery discussion.

Here for the first time was an unmediated relationship between Lynn and café family members. With all the anxiety around making meaningful experiences, emphasizing the process over the product, with the fear of being perceived as patronizing, Lynn took the risk, made the connection, and joy emerged. Roberta remembered, cared, shared, engaged, led. She stood taller. Her face lit up.

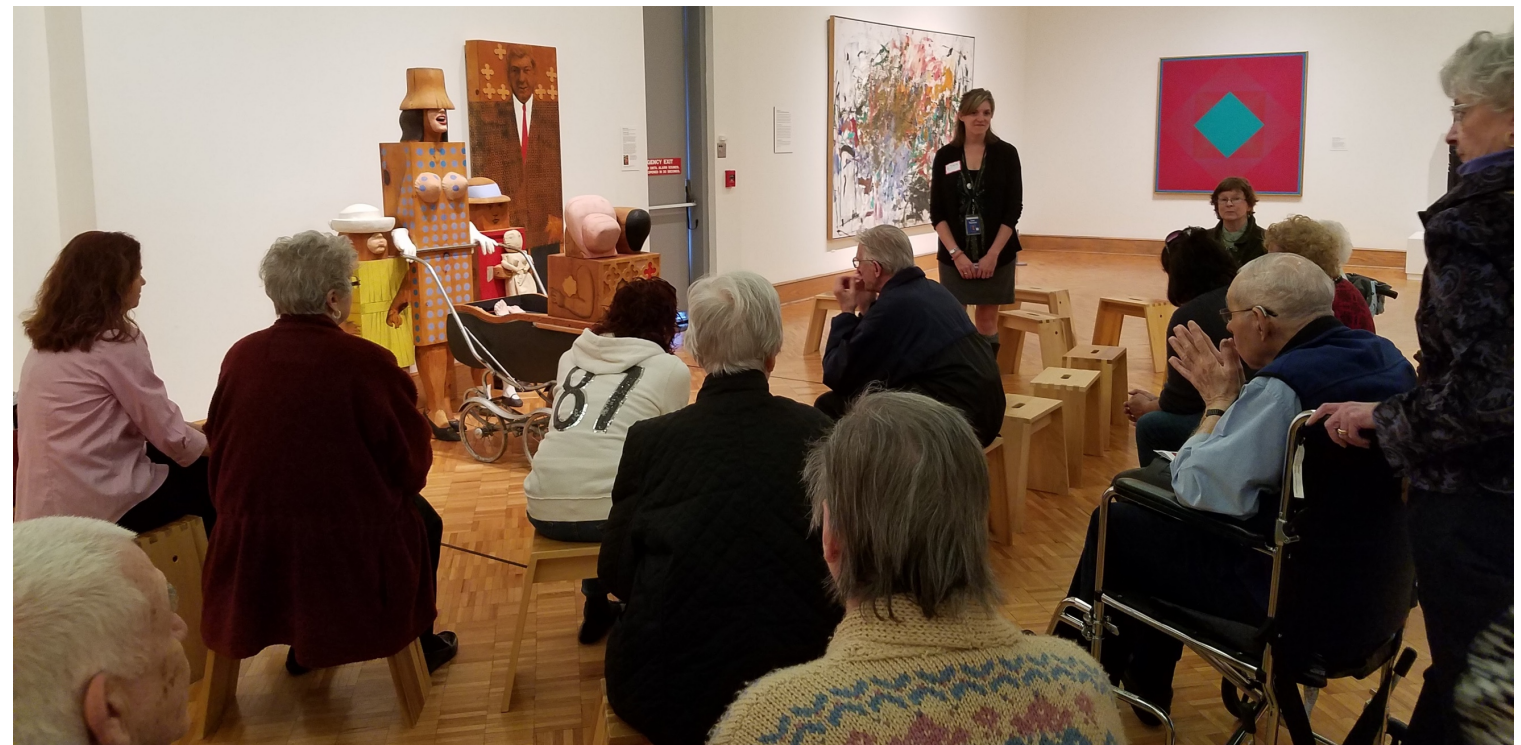

Fig. 3: Lynn leads a discussion of Marisol's The Family with the Cafe participants at the Currier Museum of Art. April 2016. Photo by Sara Clarke-Vivier. 


\section{In the End: Well-Being in Wide View}

The pilot program continued to evolve and unfold as we grew, shifted, and accepted the unknown, the unpredictable, the fluid, and flexible definitions of well-being. Emerging from a series of beliefs about the power of art, supported by a robust research literature demonstrating that participation in community arts programs is associated with improvements in older adult's physical and social well-being (Phinney, Moody, \& Small, 2014) and now finally borne out in our daily experiences, the team was faced with a final programming challenge.

The group had met for three months and made numerous art projects and had wonderful discussions about art. Now what? As a way to celebrate the program and to share the art that participants created, we decided to have an exhibition of the artwork in the Currier's Community Gallery space. Currier and Easter Seals NH staff spent a great deal of time in the weeks leading up to the exhibition discussing the shape of the show and what we did, and did not, want the exhibition's message to be. The biggest concern was that if we simply put the work on the walls it might elicit a negative reaction. Again, anxieties that people, particularly caregivers, might think that the end product wasn't "good," emerged all around. Though we had worked hard to mitigate against these fears internally, we still harbored doubts about our ability to communicate the well-being of these participants to loved ones. It was important that the participants and family members felt good about the program and appreciated the value of the process of making the art over the end result. The challenge became in how to put that complex story in a visual form for everyone to see. Additionally, since the exhibition would be on view in a public space within the museum we also wanted to be sure the exhibition would resonate with general visitors on a deeper level than "how nice, what a great program."

We would display the artwork, photos of the group making the art, and quotes from the participants. All of these would assist in illustrating the process. We also chose to include information about Alzheimer's as a way to educate viewers about the disease and its progression. All of these elementsquotes, photos, art, and definitions-were interwoven throughout the space to tell a story about wellbeing. That story, more than the art, became the center point of the exhibition. 


\section{"Experience This Moment"}

The day of the exhibition opening staff remained apprehensive about how it would be received by participants and family members. As guests entered, the space instantly filled with a palpable sense of joy. Artists were finding pictures of themselves and reading their quotes to one another. They were showing off their art to friends and family who looked on with pride and excitement. The opening highlighted the process and the importance of a program that allows for self-expression and positive social interaction with others.

In three simple words, the exhibition's title tells something of our story.

\section{Snapshot Five: Lynn at the "Experience This Moment" gallery opening}

The long, narrow Community Gallery hallway is full of participants and caregivers all looking for images of themselves. Smiles and joyful energy fill the space as family members talk with one another about the art and the quotes and as participants excitedly talk amongst their peers about what they are seeing. We read their reflections on the wall:

First of all, making art is challenging. I find it fascinating; it is something different that I've really never devoted time to before. I like painting because I feel like I'm accomplishing something. You don't necessarily have to have a good memory to make art: you need to have concentration on what you are doing. I would like to do more art. (Al, an Adult with Early Onset Dementia)

Doing art is a lot of fun. I love to make art so people can enjoy it and because it is a good thing to keep busy. You don't need to have a good memory to make art; I can handle it the way I am. I sit there, take the paper, design it, and make it. It makes me feel very good and I am glad I can still do it. I've been doing art for a long time and I'm not about to stop now. (Lorraine, an Adult with Early Onset Dementia)

Many did not remember being photographed, or their art making process, or the sharing [of] their perspectives in final interviews. But it didn't matter. People were excited and proud of their art. Caregivers saw the whole picture.

Here, in the voices of senior participants, another set of definitions emerges. Art making provided Al with the opportunity to explore something new, to spend concerted time and effort on a different project, to stretch his concentration, and to acknowledge that his memory challenges needn't interfere with any of these endeavors. For Lorraine, enjoyment and positive feelings emerge from art making. She is connected to her past, and to others, through art. Both $\mathrm{Al}$ and Lorraine imagine their own futures as including art making; they're not about to stop now. 


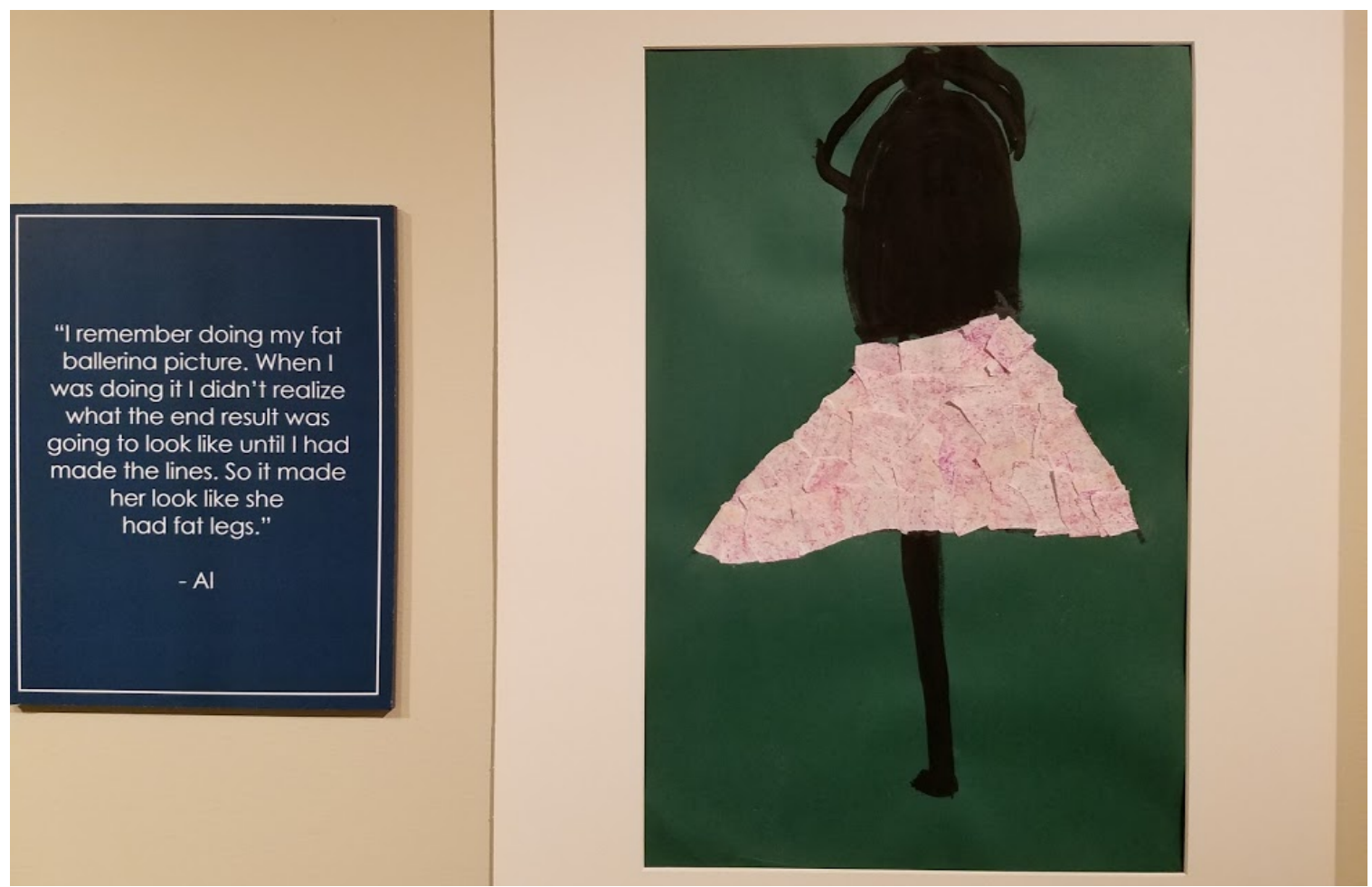

Fig. 4: Al's Degas-inspired ballerina and reflection quote from "Experience this Moment" gallery exhibition. Currier Museum of Art. May 2016. Photo by Sara Clarke-Vivier.

Here, too, Al knows his ballerina is different. He acknowledges that the process was murky for him, and that his ballerina emerged strange as a result. When Lynn and Corie decided to put this quote next to the ballerina in the gallery, they made space for the open acknowledgment of the strangeness by those others, namely the caregivers, who may have struggled with the nature of their parents' work early on. As we revisited this image as authors, Sara asked Corie to recall the context of Al's comment. "Al knew he was being funny," She said. "He wanted to make people laugh every time he talked about his fat ballerina. Ballerinas can't be fat, he would say, they have to dance. He had cracked a really successful joke, and he returned to it time and again."

The gallery opening provides us with concentrated, positive feedback from participants and caregivers alike. After it all, Laurie, the director of the Easter Seals program, whose care was demonstrated as she showed Sara the neat red barns, told us that to her, the process was directly related to participant wellness.

There is a direct correlation between art and wellbeing. The use of art can help people with mood as it can promote relaxation, improve mood and may help concentration and restlessness. For people who may not have verbal skills it is a way to express themselves- a need to be heard and recognized and that is always good for the soul. Art is a non-judgmental medium where there is no right or wrong and when done with others, it is an opportunity to engage in a social setting. (L. Duff, personal communication, January 2017)

Art is nonjudgmental. There is no right or wrong when done socially with others. 


\section{In Closing}

\section{Snapshot six: Corie at the "Experience This Moment" gallery opening}

I'm chatting with the wife of one of my students. When I meet people from this program, I always assume that they have been married to their spouses for a long time because they are senior citizens. In this case I'm wrong. This wife, whose husband is lively and sweet and funny and in a fairly advanced stage of dementia, has only been married to him for about six years. The Alzheimer's began to manifest after they had been married for just one year, completely changing their ability to communicate. She shares that because it came on so quickly and after they had known each other for only a relatively short period of time, she has had to get to know her husband in other ways. One way has been by seeing her husband's artwork from this program, both the finished piece at the end as well as photos of him working which show his methodical and thoughtful process. It is an emotional conversation. As we finish talking, her husband, who had been sitting quietly during most of the reception, spontaneously breaks into song with a big, happy smile on his face. Although bittersweet, this exchange is a moment of joy.

Experience this moment. 


\section{References}

Alzheimer's Association (AA). (2017). 2016 Alzheimer's Disease Facts and Figures. Retrieved from http://www.alz.org/facts/

American Alliance of Museums (AAM). (2013) Museums on call: How museums are addressing health issues. American Alliance of Museums. Retrieved from http://www.aam-us.org/docs/defaultsource/advocacy/museums-on-call.pdf?sfvrsn=8

Bonoti, F., Tzouvaleka, E., Bonotis, K., \& Vlachos, F. (2015). Do patients with Alzheimer's disease draw like young children? An exploratory study. Journal of Alzheimer's Disease, 43, 1285-1292.

Currier Museum of Art. (n.d.) Adult Programs: Alzheimer's Café. Retrieved from http://www.currier.org/programs/adult-programs/

Dean, R., Proudfoot, R., \& Lindesay, J. (1993). The quality of interactions schedule (QUIS): Development, reliability and use in the evaluation of two domus units. International Journal of Geriatric Psychiatry, 8(10), 819-826.

Denzin, N. K., \& Lincoln, Y. S. (Eds.). (1999). The SAGE handbook of qualitative research (3rd ed.). Thousand Oaks, CA: Sage Publications.

Flatt, J., Liptak, A., Oakley, M., Gogan, J., Varner, T., \& Lingler, J. (2015). Subjective experiences of an art museum engagement activity for persons with early-stage Alzheimer's disease and their family caregivers. American Journal of Alzheimer's Disease and Other Dementias, 30(4), 380-389.

Gretton, C., \& Fftyche, D. (2014). Art and the brain: a view from dementia. International Journal of Geriatric Psychiatry, 29, 111-126.

Kincheloe, J. L. (2005). On to the next level: Continuing the conceptualization of the bricolage. Qualitative Inquiry, 11(3), 323-350.

Mangione, G. (2013). Access to what? Alzheimer's disease and esthetic sense-making in the contemporary art museum. Poetics, 41(1), 27-47.

Marshall, M. J., \& Hutchinson, S. A. (2001). A critique of research on the use of activities with persons with Alzheimer's disease: A systematic literature review. Journal of Advanced Nursing, 35(4), 488-496.

Museum of Modern Art, The (MoMA). (n.d.). The MoMA Alzheimer's Project: Making Art Accessible to People with Dementia. The Museum of Modern Art. Retrieved from https://www.moma.org/momaorg/shared/pdfs/docs/learn/GuideforMuseums.pdf

Phinney, A., Moody, E., \& Small, J. (2014). The effect of a community-engaged arts program on older adults' wellbeing. Canadian Journal on Aging, 33(3), 336-345.

Putland, C. (2008). Lost in translation: The question of evidence linking community-based arts and health promotion. Journal of Health Psychology, 13, 265-276.

Rogers, M. (2012). Contextualizing theories and practices of bricolage research. The Qualitative Report, 17(48), 1-17. 
Rosenberg, F. (2009). The MoMa Alzheimer's Project: programming and resources for making art accessible to people with Alzheimer's disease and their caregivers. Arts \& Health, 1(1), 93-97.

Selberg, S. (2015). Modern art as public care: Alzheimer's and the aesthetics of universal personhood. Medical Anthropology Quarterly, 29(4), 473-491.

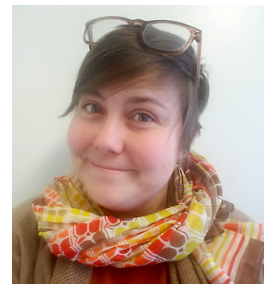

Sara Clarke-Vivier is an Assistant Professor of Education at Washington College in Chestertown, Maryland. Her research explores teaching and learning at the intersections of formal and informal spaces, such as schools and museums. She is particularly interested in how issues of conflict, complexity, and controversy emerge and are navigated by educators at these intersections. Sara holds a PhD in Curriculum and Instruction from the University of New Hampshire as well as undergraduate and master's degrees in developmental psychology and human development and learning.

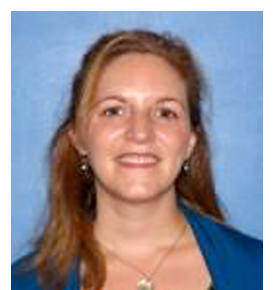

Lynn Thomson, Manager of Family Programs and Community Engagement, has a BA in Photography from Lesley University and a MA in Museum Education from Tufts University. In her role at the Currier she develops programs for children, families, and adults. Her passion lies in working with community organizations to connect underserved audiences, including seniors and Veterans, with art. Prior to the Currier, Lynn worked at the deCordova Sculpture Park and Museum in Lincoln, MA for 12 years and held various positions, including Acting Director of Education.

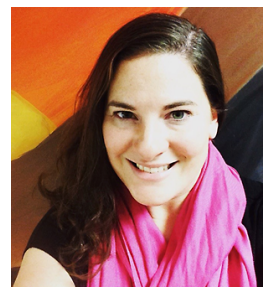

Corie Lyford, Outreach Coordinator and Assistant Art Camp Program Manager at the Currier Museum Art Center, is a graduate of Bridgewater State College in Art and English. As a painter, she is inspired by New England landscapes and architecture and exhibits her acrylic and collage pieces locally. In addition to her management responsibilities, she has served as an instructor in the youth and outreach programs at the Art Center for the past 10 years. Corie has a specialized interest in developing and teaching art curriculums designed specifically for people with Alzheimer's disease and related dementias as well as adults with developmental disabilities. 